\title{
HET BELGISCH KONINKLIJK BESLUIT MET BETREKKING TOT DE JAARREKENING VAN DE ONDERNEMINGEN
}

\author{
door Dr. R. Vertonghen')
}

\section{Inleiding}

In het Belgisch Staatsblad van 19 oktober 1976 verscheen het „Koninklijk Besluit van 8 oktober 1976 met betrekking tot de jaarrekening van de ondernemingen”. Dit Koninklijk Besluit vloeit voort uit de wet van 17 juli 1975 met betrekking tot de boekhouding en de jaarrekeningen van de ondernemingen. Deze wet is te zien als een basis- of kaderwet, die een aantal algemene principes vastlegde met be trekking tot de boekhouding en de jaarrekening van de ondernemingen, maar die verder de mogelijkheid voorzag om later verschillende uitvoeringsbesluiten uit te vaardigen. De belangrijkste te verwachten besluiten waren de volgende:

1) Bepaling van de inhoud en de indeling van een als minimum geldend genormaliseerd boekhoudkundig plan (rekeningstelsel), alsook bepaling van wat de in het genormaliseerd plan opgenomen rekeningen moeten bevatten en hoe ze werken (Art. 4 ; lid 6).

2) Het voorschrijven van maatstaven voor de inventarisraming (waarderings. grondslagen) alsook van de vorm en de inhoud van de jaarrekening (Art. 7; lid 4).

Met ,jaarrekening" wordt hier bedoeld de interne jaarrekening, d.i. de beschrijvende staat die wordt opgesteld door de rekeningen van de saldibalans te groeperen in balans. en resultatenrekeningen, nadat ze in overeenstem. ming zijn gebracht met de gegevens van de fysieke inventaris.

3) Bepaling van de vorm en de inhoud van balansen en resultatenrekeningen die krachtens de wet moeten worden neergelegd of bekendgemaakt, alsook bepaling van de inhoud van de toelichting die zoals de balans en de resulta. tenrekening neergelegd of bekendgemaakt moet worden (Art. 10). Hier be. treft het dus - in tegenstelling tot de in punt 2 bedoelde normen inzake de interne jaarrekening - normen inzake de externe jaarrekening.

4) Verplichting tot het opmaken en bekendmaken van geconsolideerde rekeningen en het stellen van regels met betrekking tot die rekeningen (art. 11, $1^{\circ}$ ). $\mathrm{Na}$ een aantal uitvoeringsbesluiten van formele aard - waaronder de oprichting van een commissie voor boekhoudkundige normen, belast met de uitbouw van een „boekhouddoctrine” en het formuleren van adviezen en aanbevelingen - is thans met het K.B. van 8 oktober 1976 het eerste van bovengenoemde reeks belangrijke besluiten verschenen. Het heeft betrekking op de punten 2 en 3, m.a.w. het regelt de vorm en inhoud van de interne jaarrekening van de ondernemin. gen, het schrijft waarderingsregels voor en het bepaalt de vorm en inhoud van de externe jaarrekeningen. Voor de punten 1 en 4 zijn nog geen regelingen ver. schenen.

Aangezien de publikatie van het K.B. van 8 oktober 1976 een uiterst belangrijke Belgische ontwikkeling vormt op het vlak van de wettelijke verplichtingen inzake

\footnotetext{
I De auteur is eerstaanwezend assistent aan de Faculteit der Economische en Toegepaste Economische Wetenschappen van de K.U. Leuven. Hij dankt Prof. drs. G. G. M. Bak. R.A., openbaar accountant en buitengewoon hoogleraar aan de Katholieke Hogeschool te Tilburg voor zijn waardevolle opmerkingen en suggesties bij de opbouw van dit arrikel.
} 
de financiële verslaggeving van de ondernemingen, lijkt het ons verantwoord er nader op in te gaan.

\section{Specifieke studie van het K.B. m.b.t. de jaarrekening van de ondernemingen}

\section{A. Algemeen}

Het K.B. is rechtstreeks ingegeven door de huidige stand van het ontwerp van vierde richtlijn van de Europese Gemeenschap, zij het dat omwille van de typisch Belgische situatie mede rekening werd gehouden met de aanbevelingen geformuleerd door de Centrale Raad voor het Bedrijfsleven en met de adviezen opgesteld door de commissie voor boekhoudkundige normen. De bedoeling van het K.B. is te komen tot een jaarrekening die een duidelijk beeld van de onderneming geeft, als ,dynamisch en duurzaam georganiseerd geheel van mensen, van technische middelen en van kapitalen, ingericht met het oog op het voeren van een economische activiteit die moet leiden tot het tot stand brengen van een brutoprodukt, dat toelaat aan allen die tot deze realisatie van dit produkt hebben bijgedragen, bruto of netto-inkomen toe te kennen".

Het K.B. is bijgevolg opgesteld in het kader van de moderne visie van de onderneming als sub systeem binnen het omvattend systeem van de maatschappelijke voortbrenging. De economische en sociale betekenis van de onderneming in de maatschappij neemt toe. Wat de onderneming doet, is mede bepalend voor de welvaart en het welzijn, in het bijzonder van allen die daar direct bij betrokken zijn, maar daarnaast eveneens van de gemeenschap als geheel. De informatieverschaffing over de financiële toestand en de resultaten van de onderneming aan het maatschappelijk verkeer - aandeelhouders, schuldeisers, leveranciers, werk. nemers, overheid - dient door deze realiteit ingegeven te zijn. De jaarrekeningen van de ondernemingen dienen dan ook beter geschikt te worden gemaakt voor integratie in de nationale rekeningen, zelfs al moet worden erkend dat ze de maatschappelijke betekenis van de onderneming niet volledig tot uitdrukking kunnen brengen. De bestanddelen van het vermogen worden meer beschouwd in termen van economisch nut dan in termen van te realiseren waarden. De economische betekenis van de bedrijfsgebeurtenissen prevaleert boven de fiscale en juridische benadering en wordt bijgevolg in de verslaggeving geaccentueerd.

Volgens deze visie verwerft de resultatenrekening een essentiële betekenis, even belangrijk als, zoniet belangrijker dan de balans. Men zal immers aan de hand van de resultatenrekening een inzicht willen krijgen in de inkomensvor. ming en in de inkomensverdeling die in de onderneming plaatsheeft. Daarom heeft men in het K.B. ook de voorkeur gegeven aan het eerste schema van de resultatenrekening voorzien door het ontwerp van vierde richtlijn van de E.E.G., dat de opbrengsten en de kosten naar hun aard op het voorplan stelt. De door de onderneming gerealiseerde toegevoegde waarde wordt hierin expliciet gemaakt.

\section{B. Toepassingsgebied van het $K . B$.}

Het K.B. geldt in principe voor alle grote ondernemingen, dit zijn de ondernemingen die aan minstens één van onderstaande voorwaarden voldoen:

1) gemiddeld meer dan 50 personen per jaar in dienst hebben; 
2) het voorgaand boekjaar een omzet verwezenlijkt hebben van meer dan 50 miljoen frank, exclusief B.T.W.;

3) in voorgaand boekjaar een balanstotaal van 25 miljoen frank overschreden hebben; daarbij verstaat men onder balanstotaal het bedrag zoals dit uit de toepassing van het K.B. zal voortvloeien.

Worden evenwel steeds met de grote ondernemingen gelijkgesteld, ongeacht hun aantal tewerkgestelden, omzet of balanstotaal, zodat het K.B. er eveneens van toepassing op is:

- de wisselagenten

- hypothecaire kredietinstellingen, kapitalisatiemaatschappijen en de verzeke. ringsmaatschappijen die niet beheerst worden door de wetgeving betreffende de controle op de verzekeringsmaatschappijen.

Het K.B. dient niet te worden toegepast door bepaalde categorieën van ondernemingen die door bijzondere wetten beheerst worden:

1) de banken, private spaarkassen en andere financiële instellingen alsook beleggingsmaatschappijen die onderworpen zijn aan de controle van de Bank. commissie;

2) kredietinstellingen beheerst door een bijzondere wet en de kredietverenigingen die door deze instellingen zijn erkend (bijv. de Nationale Maatschappij voor Krediet aan de Nijverheid, de Algemene Spaar. en Lijfrentekas, de Nationale Maatschappij voor Huisvesting);

3) de verzekeringsmaatschappijen die zijn toegelaten op grond van de wetgeving betreffende de controle op de verzekeringsondernemingen.

Voor deze ondernemingen zullen namelijk afzonderlijke bepalingen ingevoerd worden die parallel lopen met het K.B. maar die specifiek zijn voor de sector. Vermeldenswaardig is nog dat ook de buitenlandse ondernemingen voor de „succursalen en bedriffzetels die ze in België hebben gevestigd" onderworpen zijn aan de bepalingen van het K.B., althans indien ze beantwoorden aan bovengenoemde voorwaarden die het toepassingsgebied afbakenen (zie Art. 1 van het K.B., alsook Art. 1 van de wet van 17 juli 1975). Daarbij wordt het geheel van hun succursalen en bedrijfszetels in België als een onderneming beschouwd. De boeken, rekeningen en verantwoordingsstukken m.b.t. die succursalen en zetels dienen in België te worden gehouden en bewaard.

\section{Structurele voorstelling van het K.B.}

Het K.B. omvat vier hoofdstukken:

- Hoofdstuk I: Vorm en inhoud van de jaarrekening

- Hoofdstuk II: Waarderingsregels

- Hoofdstuk III: Vorm en inhoud van de balans en van de resultatenrekening die krachtens de wet moeten worden neergelegd of bekendgemaakt

- Hoofdstuk IV: Diverse en overgangsbepalingen.

Achtereenvolgens zullen we de belangrijkste bepalingen en bijzondere punten die nadere aandacht vragen m.b.t. elk hoofdstuk behandelen.

\section{1) Hoofdstuk I. Vorm en inhoud van de jaarrekening}

In dit hoofdstuk worden de bepalingen opgenomen m.b.t. de normen van de interne jaarrekening. Deze omvat: de balans, de resultatenrekening en de toelichting. Het weze opgemerkt dat de jaarrekening onderscheiden wordt van het ver- 
slag van de commissarissen en van het verslag van de beheerders of zaakvoerders.

De jaarrekening moet worden opgesteld overeenkomstig een welbepaald sche$m a$ dat in bijlage bij het K.B. wordt voorgeschreven. De balans moet in scontrovorm voorgesteld worden. De resultatenrekening wordt naar keuze voorgesteld in scontro- of staffelvorm. De toelichting wordt gevormd door een geheel van inlichtingen ter aanvulling van de balans en de resultatenrekening. In vergelijking met de balans, die nauw aansluit bij de traditionele Belgische opvattingen, wijkt de resultatenrekening daar sterker van af, gegeven de uitgebreidheid van de voorgeschreven rubrieken, de verplichting de omzet bekend te maken (op uitzondering van de zgn. ,kleinere” grote ondernemingen; $\mathrm{cf}$. infra) alsook de samen. stellende delen van de resultaten te analyseren, waarbij een onderscheid moet ge. maakt worden tussen bedrijfsresultaten, financiële resultaten, uitzonderlijke resul. taten, en belastingen op winst. Bovendien moet als aanvulling de bestemming van de resultaten worden vermeld. De balans moet namelijk opgesteld worden na toewijzing, d.w.z. na rekening te hebben gehouden met de beslissingen inzake besteding van de beschikbare winst of de toewijzing van het eventueel verlies. In. dien nog geen definitieve beslissing omtrent de bestemming is genomen, moet de jaarrekening opgesteld worden onder de opschortende voorwaarden van die beslissing.

Als algemeen voorschrift geldt dat de jaarrekening duidelijk moet worden opgesteld; ze moet getrouw en stelselmatig weergeven, enerzijds, op de dag waarop het boekjaar wordt afgesloten, de aard en het bedrag van de tegoeden en rechten van de onderneming, van haar schulden, van haar verplichtingen en verbintenissen evenals van haar eigen middelen, anderzijds, voor het op die dag afgesloten boekjaar, de aard en het bedrag van haar kosten en haar opbrengsten.

Om aan bovenstaand beeld te voldoen, worden een aantal regels opgelegd, die behoren tot de klassieke boekhoudkundige principes. Nochtans blijft als belang. rijkste eis gelden dat de jaarrekening een getrouw en klaar beeld moet geven van de werkelijke toestand en resultaten van de onderneming. Het K.B. verplicht in derdaad tot afwijking van de regels onder bepaalde voorwaarden, wanneer de toepassing van deze regels leidt tot een vertekend beeld van de reële situatie. Daardoor tracht men te vermijden dat de onderneming zich alleen maar strikt formeel zou houden aan de letter van de boekhoudwet. Aldus stelt het K.B. dat in principe de voorstelling van de jaarrekening identiek moet zijn van het ene jaar tot het andere, maar dat ze toch mag gewijzigd worden als het algemeen geldend voorschrift van oprechtheid en getrouwheid dat vereist. De wijzigingen dienen wel vermeld en verantwoord te worden in de toelichting.

Op enkele uitdrukkelijk genoemde rubrieken van de toelichting na, dienen de vergelijkende bedragen van het vorige boekjaar te worden vermeld. Ingeval van een (uitzonderlijke!) verandering in de wijze van presentatie van de jaarrekening worden de bedragen van het vorig boekjaar omwille van de vergelijkbaarheid aangepast bij toepassing van de criteria die voor het nieuwe boekjaar gelden. In dat geval wordt uitdrukkelijk vermeld dat het aangepaste rekeningen betreft.

Te noteren valt dat de gecumuleerde afschrijvingen en waardeverminderingen moeten afgetrokken worden van de actiefposten waarop ze betrekking hebben. Deze actiefposten komen op de balans dus voor in de vorm van netto-be. dragen. Verder wordt het eventueel overgedragen verliessaldo uit de actiefzijde geweerd en komt op de passiefzijde voor als minderingspost van het eigen ver- 
mogen. Voorzieningen mogen geen waardecorrecties op activa bevatten.

Belangrijk is het invoeren van de verplichting dat alle verbintenissen, met in. begrip van de verbintenissen en verhaalrechten die men pleegt aan te duiden als „orderekeningen" moeten worden verwerkt volgens het systeem van dubbel boekhouden en in de balans of in de toelichting dienen vermeld te worden. Moe. ten in de balans opgenomen worden - onder een afzonderlijke subrubriek van de materiële vaste activa - de gebruiksrechten van onroerende en bepaalde roerende goederen waarover de onderneming beschikt krachtens overeenkomsten van onroerende leasing, erfrecht, opstal, huurfinanciering (leasing) of gelijkwaar. dige overeenkomsten, indien de eigendom van die goederen bij het einde van het contract, hetzij van rechtswege, hetzij krachtens koopoptie overgaat naar de huurder. Overeenkomstig zullen de schulden die voortvloeien uit deze contracten moeten ingeschreven worden onder een afzonderlijke subrubriek van de schul. den op langer dan een jaar. In samenhang hiermee, tenslotte, zal de eigenaar of ontlener in zim balans, onder een afzonderlijke subrubriek van de ,financiële vaste activa" het bedrag moeten inschrijven dat overeenstemt met de schuld die de erfpachter of huurder zal inschrijven in de voornoemde subrubriek op het passief van zijn balans.

Een ander vermeldenswaardig voorschrift m.b.t. de inhoud van de balans is dat, onder de subrubriek „pensioenfonds" van de schulden op langer dan een jaar de voorzieningen moeten geboekt worden die gevormd worden met het oog op alle of een deel van de verplichtingen die voortspruiten uit overeenkomsten af. gesloten tussen de onderneming en het personeel of de directie, inzake aanvul. lende rust- en overlevingspensioenen ter aanvulling van het wettelijk stelsel, en waarop de begunstigden zich in rechte en in feite mogen beroepen, wanneer de verplichtingen die er voor de onderneming uit voortvloeien niet door een ver. zekeringscontract gedekt zijn. Nochtans zal de verplichting deze schuld op het pas. sief in te schrijven slechts verplicht gesteld worden op de datum en volgens de modaliteiten die door een later K.B. zullen vastgesteld worden. Alleszins legt het K.B. vanaf zijn inwerkingtreding de verplichting op in de toelichting een beknopte beschrijving te geven van het aanvullend pensioenstelsel, alsook van de maatregelen die door de onderneming getroffen werden om de daaruit voortvloeiende lasten te dekken.

\section{2) Hoofdstuk II. Waarderingsregels}

In dit hoofdstuk worden de criteria en de methode van waardering voorgeschreven. Overeenkomstig het voorstel van richtlijn van de E.E.G. behoudt het K.B. de aanschaffingswaarde als basisbeginsel voor de waardering van activa. Nochtans is men in België, net als in de meeste andere landen ervan overtuigd dat men, bij het bepalen van waarderingsregels, de gevolgen van de inflatie en van prijsstij. gingen op de oprechtheid van de jaarrekening niet kan miskennen. Bij gebrek aan een gevestigde doctrine en van beproefde methoden heeft men echter de inflatieboekhouding in de strikte zin van het woord niet willen toelaten noch a fortiori er de toepassing van willen opleggen. Niets belet de ondernemingen evenwel in hun verslag erop te wijzen - met vermelding van de gebruikte methode - welke invloed de toepassing van een techniek van inflatieboekhouding op het vermogen of op de winsten van de onderneming zou gehad hebben. Daarenboven om. vat het K.B., hoewel het het principe van de waardering tegen aanschaffings. 
waarde behoudt, toch een aantal bepalingen waardoor de prijsevolutie in acht kan worden genomen.

Op de eerste plaats mag de aanschaffingswaarde van de voorraden van goederen die identieke kenmerken vertonen bepaald worden aan de hand van de LIFO-methode, zij het dat waardering volgens de FIFO-methode of tegen gewogen gemiddelde prijzen eveneens geoorloofd is (Art. 33).

Vervolgens mogen de materiële, de immateriële en de financiële vaste activa, bij een vaststaande en blijvende meerwaarde ten aanzien van hun aanschaffings. waarde, geherwaardeerd worden teneinde ze een waarde toe te kennen die meer met de werkelijkheid overeenstemt (Art. 34). De uit de herwaardering voortvloeiende meerwaarden moeten, tenzij ze in het kapitaal ingelijfd worden, ingeschreven blijven op een speciale rubriek van het passief (nl. de rubriek „herwaarderingsmeerwaarden") tot de geherwaardeerde activa gerealiseerd of buiten gebruik gesteld worden.

Tenslotte mag voor de materiële vaste activa met beperkte levensduur evenals voor de voorraden geopteerd worden voor een waardering volgens de methode van de vervangingswaarde, en mogen die vaste activa op basis van deze waarde afgeschreven worden (Art. 35). In dat geval moeten de ondernemingen:

a) het toepassen van dat regime en de modaliteiten ervan in de toelichting ver. melden;

b) het verschil tussen de vervangingswaarde en de aanschaffingswaarde op het passief boeken onder de rubriek "herwaarderingsmeerwaarden" zolang de daar opgenomen bedragen nodig zijn voor het behoud van het potentieel van de onderneming:

c) de afschrijvingen voor elk boekjaar berekenen op basis van de voor het betrokken boekjaar in aanmerking genomen vervangingswaarde.

België heeft bijgevolg gebruik gemaakt van de mogelijkheid die art. 30 van het voorstel van vierde richtlijn van de E.E.G. biedt om waardering tegen vervangingswaarde van materiële vaste activa en voorraden toe te staan. Het dient even wel opgemerkt te worden dat het begrip vervangingswaarde en de concrete toepassing ervan in het K.B. niet bepaald worden. Verder dient de aandacht erop gevestigd te worden dat, in de huidige stand van de Belgische fiscale wetgeving, de op voorraden uitgedrukte meerwaarden onmiddellijk belastbaar zouden zijn, terwijl de afschrijvingen niet fiscaal aftrekbaar zouden zijn in die mate waarin ze betrekking hebben op het bedrag dat de aanschaffingswaarde te boven gaat. Dit zou betekenen dat op de toepassing van vervangingswaarde in de jaarrekening in feite de sanctie zou staan van belastingheffing over de nog niet gerealiseerde waardestijgingen van activa. Praktisch zou dat een vrijwel absolute verhindering betekenen om dit stelsel te laten doorbreken. In dit verband zij wel vermeld dat de fiscale standpunten en consequenties met betrekking tot de nieuwe regelingen van het K.B. nog in studie zijn en dat men binnen afzienbare tijd aanpassingen mag verwachten. Men notere tenslotte het onderscheid in behandeling van de meerwaarden voortvloeiend enerzijds uit de toepassing van artikel 34 (mogelijkheid activa te herwaarderen), en anderzijds uit de toepassing van artikel 35 (waardering volgens de methode van de vervangingswaarde): voor een volgens artikel 34 geherwaardeerd activum wordt zijn meerwaarde, onverminderd de mogelijk. heid om ze op elk moment in het kapitaal in te lijven, bij de realisatie of buiten gebruikstelling op de resultatenrekening ingeschreven; voor een activum waarop 
men de vervangingswaardemethode toepast, moet de meerwaarde slechts in de resultatenrekening opgenomen worden wanneer ze niet meer nodig is ,voor het behoud van het potentieel van de onderneming" en ze mag in geen enkel ander geval op de resultatenrekening geboekt worden.

Als algemeen waarderingsprincipe geldt dat elke onderneming, met nakoming van de bepalingen van het hoofdstuk II van het K.B., doch rekening houdend met haar specifieke kenmerken, haar eigen waarderingsregels moet bepalen. Deze regels moeten in de toelichting samengevat worden. Voor welke waarderingsregels de onderneming binnen het kader van de wettelijke voorschriften ook opteert, deze waarderingsregels moeten stelselmatig worden toegepast. In het bijzonder mogen de afschrijvingen, waardeverminderingen en voorzieningen voor risico's en lasten niet afhankelijk worden gesteld van het resultaat van het boekjaar. Er moet rekening gehouden worden met alle te voorziene risico's, mogelijke verlie. zen en ontwaardingen, zelfs voor feiten $n a$ balansdatum. De waarderingen, af schrijvingen, waardeverminderingen, voorzieningen voor risico's en lasten en de andere voorzieningen moeten beantwoorden aan normen van voorzichtigheid, oprechtheid en goede trouw. Er moet rekening gehouden worden met de kosten en opbrengsten die betrekking hebben op het boekjaar of op voorgaande boek. jaren, ongeacht de dag waarop ze zullen betaald of geïnd worden, behalve indien de effectieve inning van de opbrengsten onzeker is.

Het K.B. handhaaft bijgevolg duidelijk het traditioneel beginsel van de voorzichtigheid. Nochtans wordt het beginsel uit het gewoonterecht waarbij voorzich tigheid voorrang heeft op oprechtheid niet langer aanvaard. Verdoken winstre. serveringen worden veroordeeld. Het K.B. verbiedt inderdaad het handhaven van overdreven of niet gerechtvaardigde voorzieningen voor risico's en lasten of voor belastingen, en verplicht tot het opnieuw opnemen van voor een te hoog bedrag geboekte waardevermindering op activa.

De door de onderneming gevolgde waarderingsregels moeten in principe van het ene boekjaar op het andere identiek blijven. Ondanks dit continuiteitsbeginsel van de waarderingsregels, moeten ze echter toch gewijzigd worden indien door het toepassen ervan het beeld van de jaarrekening in strijd zou komen met het onder hoofdstuk I vermelde algemeen voorschrift van duidelijkheid en getrouw. heid. Deze wijzigingen dienen in de toelichting te worden vermeld en verant. woord, met opgave van de raming van het verschil dat eruit ontstaat. Daaruit blijkt nogmaals het grondbeginsel van het K.B. volgens hetwelk men steeds de werkelijke toestand van de onderneming moet in aanmerking nemen en volgens hetwelk de ondernemingen, binnen het kader van de wettelijke voorschriften, die regels moeten volgen die leiden tot het opstellen van klare en getrouwe jaarre. keningen. Mede met de maatregelen die in het K.B. getroffen worden om de vergelijkbaarheid van de opeenvolgende jaarrekeningen in de hand te werken, is dit een waarborg opdat alle belangstellenden zich een duidelijk beeld en bijgevolg verantwoord oordeel zouden kunnen vormen van de financiële toestand en evolutie van de onderneming.

\section{3) Hoofdstuk III. Vorm en inhoud van de balans en de resultatenrekening die krachtens} de wet moeten worden neergelegd of bekendgemaakt

Dit hoofdstuk bevat de bepalingen m.b.t. de normen die gelden voor de externe jaarrekening. Overeenkomstig het Wetboek van Koophandel dienen de naamlo- 
ze vennootschappen hun jaarrekening bekend te maken in de bijlagen tot het Bel. gisch Staatsblad; de personenvennootschappen met beperkte aansprakelijkheid en de samenwerkende vennootschappen dienen hun jaarrekening neer te leggen bij de griffie van de rechtbank van koophandel van hun bedrijfszetel, zodat elke belanghebbende er inzage kan van nemen. Het dient te worden onderstreept dat het K.B. aan deze door het Wetboek van Koophandel geregelde neerleggings- en publikatieverplichting geen wijziging aanbrengt. Het K.B. bepaalt alleen dat, voor de ondernemingen waarop het van toepassing is, die neer te leggen of te publiceren jaarrekeningen thans naar vorm en inhoud moeten beantwoorden aan de regels voorzien in het K.B.

Het algemeen voorschrift inzake neerlegging en publikatie is eenvoudig: de ex. terne jaarrekening moet, onverminderd de toepassing van bijzondere wets- of reglementsbepalingen, opgesteld worden overeenkomstig de hoofdstukken I en II van het K.B. Dit houdt in het bijzonder in dat de externe jaarrekening moet conform zijn met de in bijlage bij het K.B. opgenomen modellen van balans, resultatenrekening en toelichting. Ze moet naast elke rubriek en subrubriek de „mecanografische nummers" vermelden die in de schema's voorkomen, waardoor de verwerking van de jaarrekeningen en de inschakeling van deze gegevens in de macro-economische rekeningen zal worden vergemakkelijkt. De posten die zonder voorwerp zijn, mogen worden weggelaten. De vermeldingen die in de toelichting moeten worden opgenomen, mogen weggelaten worden indien ze van te verwaarlozen betekenis zijn.

Het K.B. voorziet verder in een beperkte publikatievorm voor de zgn. „kleinere” grote ondernemingen, dit zijn de ondernemingen die:

a) jaarlijks gemiddeld niet meer dan 100 personen tewerkstellen en

b) een omzetcijfer, B.T.W. niet inbegrepen, van niet meer dan 100 miljoen F gerealiseerd hebben $e n$

c) een balanstotaal hebben dat niet hoger is dan 50 miljoen $\mathrm{F}$ en

d) geen openbaar beroep hebben gedaan op het spaarwezen in de zin van de gecoördineerde wetten op de handelsvennootschappen en

e) geen dochter zijn van een onderneming die tot neerlegging of bekendmaking van haar rekening wettelijk verplicht is.

Deze „kleinere” grote ondernemingen mogen de gegevens verstrekt in de neer te leggen of te publiceren balans en resultatenrekening beperken tot bepaalde hoofdrubrieken en de toelichting enigszins inkorten. De meest opvallende beperking van de voorstelling is te vinden in de resultatenrekening, waar in één enkele rubriek „Brutobedrijfsresultaat” het geheel van de bedrijfsopbrengsten (met inbegrip van de omzet) en het geheel van de bedrijfskosten (op uitzondering van de afschrijvingen, waardeverminderingen en voorzieningen voor risico's en lasten) mogen samengevoegd worden. In de toelichting moet dan evenwel het totale bedrag vermeld worden van de kosten voor handelsgoederen, grondstoffen, ver. bruiksgoederen, hulpstoffen en diverse goederen en diensten.

Het zij tenslotte vermeld dat gevreesd wordt dat de nieuwe voorschriften m.b.t. inhoud en vorm van de te publiceren jaarrekeningen een aanzienlijke overbelasting van de diensten van het Belgisch Staatsblad zullen veroorzaken, wegens de belangrijke toename van de omvang van de bekend te maken jaarrekening. Om dat probleem op te lossen is thans een wetsontwerp in studie waardoor de bestaande publikatie- en neerleggingsprocedure zou gewijzigd worden. De onderne- 
mingen zouden er nog enkel toe gehouden zijn hun jaarrekening neer te leggen bij de griffie van de rechtbank van koophandel, waarna die neerlegging in de vorm van een mededeling in de bijlagen tot het Belgisch Staatsblad zou bekend gemaakt worden. Tevens zou een zgn. „balanscentrale” opgericht worden die ermee belast zou worden de verspreiding van de jaarrekeningen aan alle belang. stellenden te verzekeren.

\section{4) Hoofdstuk IV. Diverse en overgangsbepalingen}

In dit hoofdstuk worden, naast een aantal voor ons doel minder belangrijke overgangsbepalingen, specifieke richtlijnen gegeven met betrekking tot de waardering van ondernemingen in vereffening. De in hoofdstuk II besproken waarderingsregels gelden immers voor een onderneming in „going concern”. Voor een onderneming in vereffening, of voor een van een onderneming deel uitmakende activiteitsbranche of vestiging die wordt gesloten of vereffend, dienen de volgende maatregelen te worden getroffen:

a) de oprichtingskosten moeten volledig zijn afgeschreven;

b) voor de overige vaste activa moet zonodig tot aanvullende afschrijvingen of waardeverminderingen worden overgegaan om de boekwaarde terug te brengen tot de waarschijnlijke realisatiewaarde;

c) een voorziening moet worden gevormd voor de aan het personeel te betalen vergoedingen en voor de andere vereffeningskosten.

\section{Besluit}

Met de kaderwet van 17 juli 1975 en het K.B. van 8 oktober 1976 dat er als aan. vullend uitvoeringsbesluit uit voortvloeit, heeft de Belgische wetgever de sterk verouderde en ontoereikende algemene wettelijke voorschriften met betrekking tot de boekhouding van de ondernemingen willen aanpassen aan de huidige eisen van het bedrijfsleven. Volgens de kaderwet moeten, sedert 1 januari 1976, alle ondernemingen die in België een handelsactiviteit uitoefenen, een boekhouding voeren die aangepast is aan de aard en de omvang van hun bedrijvigheid en die rekening houdt met de gedetailleerde richtlijnen vervat in de wet. Het K.B., dat voor het eerst van toepassing zal zijn op de jaarrekening van de ondernemin. gen afgesloten op het einde van het boekjaar dat ingaat na 31 december 1976, verplicht de grote ondernemingen hun jaarrekening op te stellen volgens een eenvormig schema en bepaalt waarderingsregels die moeten worden in acht ge. nomen. De hoofddoelstelling is, mede via een gemoderniseerde, aangepaste, duidelijke, volledige en betrouwbare bedrijfsboekhouding, aangelegd volgens algemeen geldende principes, te komen tot een jaarrekening die een duidelijk en getrouw beeld geeft van de financiële toestand en evolutie van de onderneming, ten behoeve van de rechtstreeks in de onderneming geïnteresseerden, het publiek in het algemeen en de overheid.

Aangezien de jaarrekeningen voortaan volgens dezelfde waarderingsregels op een uniforme leest zullen worden geschoeid, zullen vergelijkingen over verscheidene boekjaren, alsook intersectoriële vergelijkingen betrouwbaarder worden. Ook zal de inschakeling van deze gegevens in de macro-economische rekeningen vergemakkelijkt worden.

Dat met betrekking tot de waarderingsregels gedetailleerde wettelijke verplich. 
tingen opgelegd worden en dat strakke voorschriften betreffende de inhoud en de vorm van de interne en externe jaarrekeningen voorgeschreven worden, houdt echter ook het gevaar in dat men zou vervallen in een verstarde situatie die geen plaats zou bieden voor vernieuwing en die zou kunnen achterlopen op de sociaal.economische realiteit. Toch scheppen de wet en het Koninklijk Besluit op verscheidene plaatsen de mogelijkheid tot wijziging, aanvulling of afwijking van de bepalingen om tegemoet te komen aan de ontwikkelingen van het be. drijfsleven. Belangrijk in dit opzicht is de mogelijkheid dat de vastgestelde regels via uitvoeringsbesluiten aangepast kunnen worden aan de specifieke toestanden van de bedrijfstakken en economische sectoren, aan bijzondere problemen van bepaalde ondernemingen en aan de evolutie van de boekhoudingsdoctrine en technieken.

Misschien had men wel wat meer vrijheid kunnen laten m.b.t. de plaats waar de informatie in de externe jaarrekening dient opgenomen te worden. Met name wordt hier bedoeld dat heel wat subrubrieken die in de balans en in de resulta. tenrekening dienen voor te komen misschien beter gespecificeerd mochten worden in de toelichting, zodat men, via balans en resultatenrekening, sneller en beter een globaal en meer overzichtelijk beeld zou krijgen van de financiële situatie van de onderneming in kwestie. Het K.B. biedt deze mogelijkheid niet, alhoewel het voorstel van vierde richtlijn van de E.E.G. een bepaling bevat waardoor be doelde werkwijze toegelaten wordt.

Verder dient opgemerkt te worden dat, in tegenstelling tot het voorstel van vierde E.E.G.-richtlijn, geen bepalingen zijn opgenomen inzake de inhoud van het verslag van de Raad van Beheer noch van de verklaring van de bedrijfsrevisor (openbare accountantsverklaring). Nochtans is het via voorschriften m.b.t. het eerstgenoemd verslag dat men de beheerders zou kunnen opleggen een persoonlijk oordeel te geven over de gang van zaken en de positie van de onderneming, alsook over de te verwachten ontwikkelingen. Anderzijds is het jammer dat de gelegenheid niet te baat werd genomen om aan de openbare accountantsverklaring meer wettelijke ruggesteun te geven.

In verband met de basiswet van 17 juli 1975 zij nog aangestipt dat deze wet enkele zeer bekritiseerde anachronismen heeft in stand gehouden. De ondernemingen zijn namelijk verplicht de verrichtingen ,zonder uitstel, getrouw en volledig en in volgorde van de datum" in te schrijven, hetzij in één enkel gewaarmerkt dagboek, hetzij in een stel speciale - al dan niet gewaarmerkte - hulpdagboeken, waarvan de gegevens dan evenwel moeten gecentraliseerd worden in één gewaarmerkt centralisatieboek; het centraliseren dient tenminste eens per maand te geschieden indien de hulpdagboeken niet gewaarmerkt zijn, of slechts tenminste eens per kwartaal indien de hulpdagboeken wel gewaarmerkt zijn. Deze regelin. gen vormen natuurlijk een hinderpaal voor het voeren van een geautomatiseerde boekhouding, hoewel de wet daar enigszins wil aan tegemoetkomen door te stellen dat de hulpdagboeken niet noodzakelijk in boekvorm maar "losbladig of op enig ander geschikt materiaal" mogen gehouden worden, wat dan echter impli ceert dat waarmerking niet kan plaatshebben en dat het centraliseren bijgevolg binnen de maand moet plaatshebben. Momenteel ligt wel een wetsontwerp ter studie dat het houden van boeken op losse bladen onder bepaalde voorwaarden zal toelaten.

Het dient trouwens voor ogen gehouden te worden dat tot heden niet voor 
alle problemen richtlijnen zijn uitgewerkt. Via toekomstig uit te vaardigen Koninklijke Besluiten zullen de huidige bepalingen van de "boekhoudwet” aange. vuld worden. Naast de reeds genoemde onderwerpen - waaronder een uniform rekeningstelsel, consolidatie, fiscale implicaties en standpunten, bijzondere geval. len voor bepaalde sectoren en ondernemingen - zijn ook nog een aantal technische problemen in studie waarover de commissie voor boekhoudkundige normen advies zal uitbrengen, bijvoorbeeld de invloed van vreemde valuta op de waardering van activa en passiva, de registratie van wisselverrichtingen, alsook de boekhoudkundige verwerking van fusies en van de inbreng van bedrijfsgehelen. Tenslotte wordt overwogen de ondernemingen het opstellen en publiceren van een financieringstabel („,cash flow statement”) voor te schrijven.

Concluderend kan gesteld worden dat de wet van 17 juli 1975 en het K.B. van 8 oktober 1976 een gunstige kentering hebben teweeggebracht t.a.v. de bestaande verplichtingen inzake boekhouding en verslaggeving van de ondernemingen. Dat betekent niet dat de huidige "boekhoudwet" zonder gebreken is, maar dat ze belangrijke verbeteringen en verbeteringsmogelijkheden bevat die het be. drijfsleven en de gemeenschap ten goede (zullen) komen.

\section{Literatuur}

- Bank Brussel Lambert: De onderneming en haar boekhouding; Wet van 17 juli 1975; Koninklijk Besluit van 8 oktober 1976, brochure werkgroep Belgisch Centrum voor Normalisatie van de Accountancy en het Re. visoraat, Brussel, 1976, 110 p.

- Belgisch Staatsblad: Wet met betrekking tot de boekhouding en de jaarrekeningen van de ondememingen, 4 september 1975 , pp. 10.847 10.851.

- Belgisch Staatsblad: Koninklijk Besluit met betrekking tot de jaarrekening van de ondernemingen, 19 oktober 1976 , pp. $13.460 \cdot 13.500$.

- R. Burgert: De vierde richtlijn der EEG-commissie omtrent de jaarrekening, M.A.B., 46ste jaargang, nr. 2, februari 1972, pp. 34.51.

- R. Burgert: Een gewijzigd voorstel vierde richtlijn der EEG.Commissie omtrent de jaarrekening, M.A.B., 48ste jaargang, nr. 5, mei 1974, pp. 205.212.

- R. Delbeke: Boekhouding en jaarrekeningen van ondernemingen, Ondernemen, 32 ste jaargang, nr. 1, janua ri 1976 , pp. $29-34$ en p. 41.

- R. Delbeke: Boekhouding en jaarrekeningen van ondernemingen Il, Ondememen, 32ste jaargang, nr 5, mei 1976, pp. $245 \cdot 251$.

- Van Dien \& Co: De wettelijke bepalingen voor het inrichten en voeren van de boekhouding, vastgelegd in de Basiswet van 17 juli 1975, Bulletin nr 1, Antwerpen, 1977, 9 p.

- Van Dien \& Co: De eisen welke door het KB van 8 oktober 1976 worden gesteld aan de interne en externe jaarrekening, Bulletin nr 2, Antwerpen, 1977, $15 \mathrm{p}$

- Generale Bankmaatschappij: Vademecum van het boekhoudrecht in België, Departement Studie, Documen tatiecentrum, Brussel 1976, 48 p.

- Kredietbank: Leidraad bij de wetgeving op de boekhouding en de jaarrekening van de ondernemingen, Be drijfseconomische Bibliotheek, Brussel, 1977, $128 \mathrm{pp}$.

- Moret \& Limperg: De jaarrekening van de ondernemingen in België, zonder datum, 26 pp. 